\title{
Forecasting Tsunamis using Ship Navigation Records
}

In recent years, the Earth has been rocked by devastating Tsunamis. The ability to predict
how intense they will be is crucia in deciding how to mitigate the effects. This is what makes the work of Daisuke Inazu at Tokyo University of Marine Science and Techology and fellow researchers so important. The Automatic ldentification Systems (AIS) on ships to monitor tsunam current has huge potential to help developing countries to forecast tsunamis so that they may reduce loss of life and infrastructure damage.

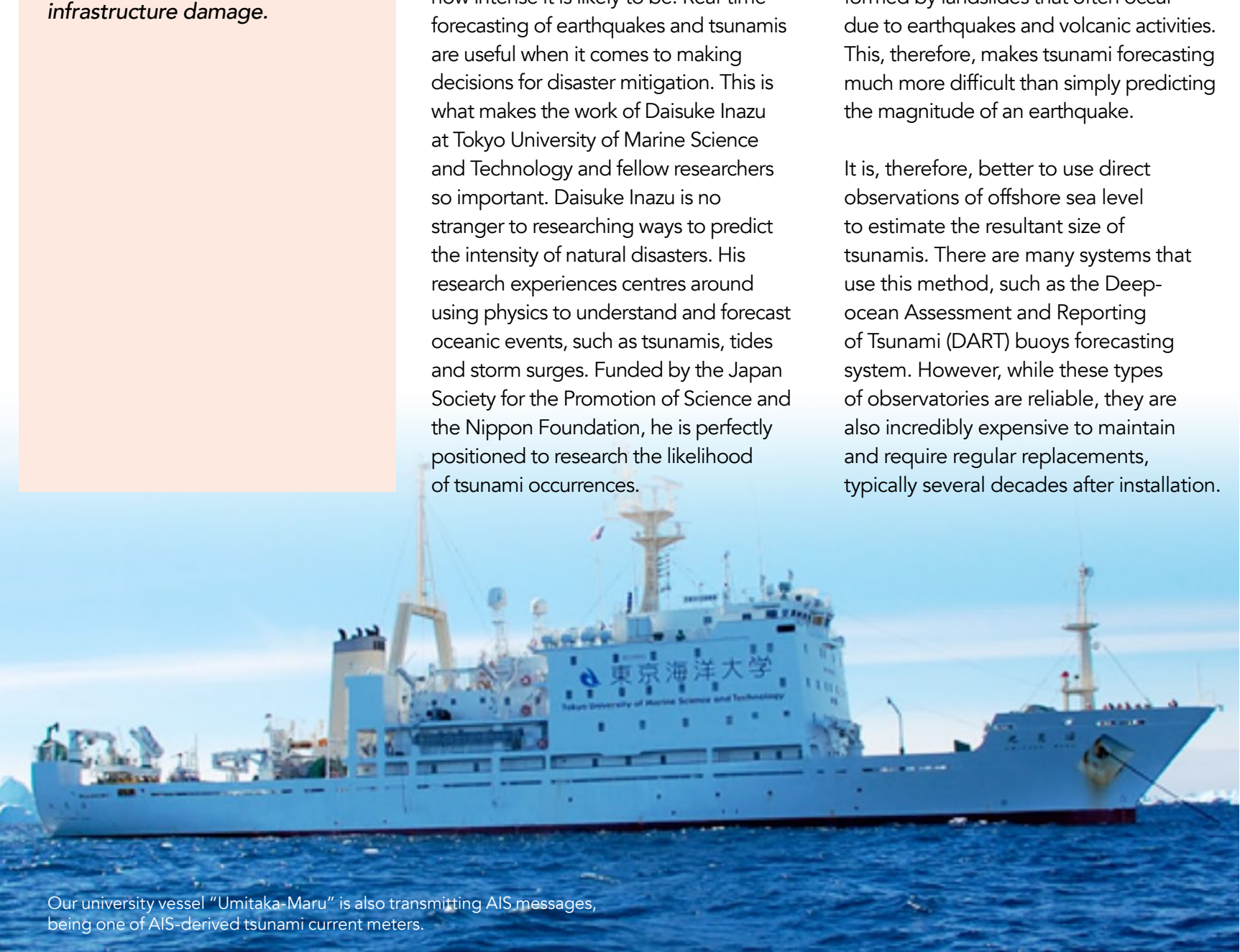
sunamis are one of the most
devastating and destructive natural
occurrences and can cause mass mortalty and infrastructure damage to be able to find ways to reduce these to be able to find ways to reduce these of individuats and he mannediate actions he occurence of a tsuisations after for reducing the loss of life that can often directly occur.

This is why it is so important to be able to tell when a tsunami is occur to tell when a tsunami is occurring, and forecasting of earthquakes and tsunam tsunamis use seismic wave observation. Selismic waves are usually generated plates. However, they can also be caused underwater. Seismic wave detection technologies are useful in regards to predicting the magnitude and intensity of an earthquake but are not always This is when forecasting tsunamis. deformation that may be indirectly related to tsunamis, and are sometimes unable to accurately predict how a tsunami will formed by landslides that often occur due to earthquakes and volcanic activities. This, therefore, makes tsunami forecasting moch difficult than simply predicting

is, therefore, better to use direct observations of offshore sea leve to estimate the resultant size of There cean Assessment and Reporting f Tsunami (DART) buoys forecasting oftem. However, while these types losses. Although some of these losses can be milgated through the use of

Most current systems in place to detect by volcanoes and landslides that occur

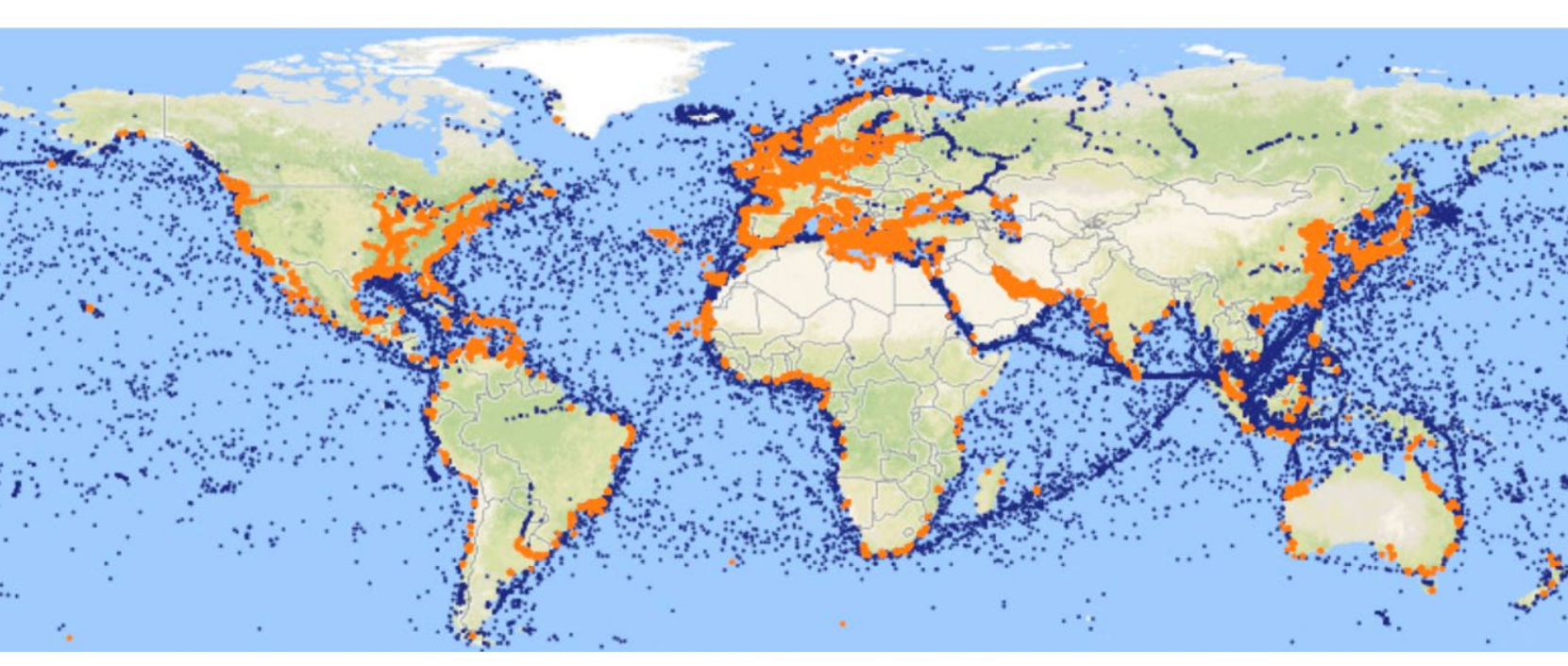

Ship distributions derived from terrestrial (orange) and satellite (blue) AlS. Adopted from Vesseltracker.com.

Since gigantic tsunamis may occur once typically during tens to hundre of years at a certain place, the cost of these observatories can add up. Offshore tsunami forecasting needs to be sustainable as well as reliable. It is therefore important that other, more sustainable, ways of monitoring and forecasting tsunamis are developed.

Inazu and his fellow researchers have conducted pioneering research into solving this issue, looking at the possibility of using Automatic Identification System (AIS) data to predict the current and height of tsunamis

\section{WHAT IS AIS DATA?}

\section{AIS data is the navigation records} he ship's latitude (SOG) course over ovround (COG) and ship heading (HDG). All of this information is used to determine the ship's position, and where it is going AIS data is collected under Internationa Maritime Organisation (IMO) regulations, which means that all ships exceeding 300 gross tonnage, and all passenger ships, are required to send this data via very-high-frequency (VHF) radio transmission. Als data from ships close to shore can be received by coastal stations, and ships further ashore can be received by low-Earh-orbit satellites. The number of ships with recognised Als data is increasing annually with increases in seabome trade and na number of can be derived from AIS data on many websites. For a pice, Als data is readly On ways in which to make AIS data more accessible in the future.

deviations under tsunami conditions. By conducting a quantitative investigation, hese deviations were used as a proxy to and could help to $p$ the

The number of ships recognised by the AIS is continually increasing, meaning more and more data can be used around to the world to forecast and measure tsunamis.

\section{HOW CAN AIS DATA HELP}

TO FORECAST TSUNAMIS?

While AIS data has not been traditionally used to forecast tsunamis, it is predicted to be useful because it enables sudden changes in the position of ships to be seen, which could help to monitor tsunam and his research team are working on contributing to the lack of research

regarding the use of AIS data to forecast tsunamis. By using data from the devastating 2011 Tohoku earthquake and resultant tsunami, they have investigated the relationship between ship horizonta drift and tsunami current.

The 2011 Tohoku earthquake caused a tsunami that reached coasts with significant wave heights (greater than 10 m) a few tens of minutes after the tsunam generation. Inazu and his research team used AIS data obtained from 16 differe ships that were out at sea during this tsunami. They found that measurem 2011 Tohoku As

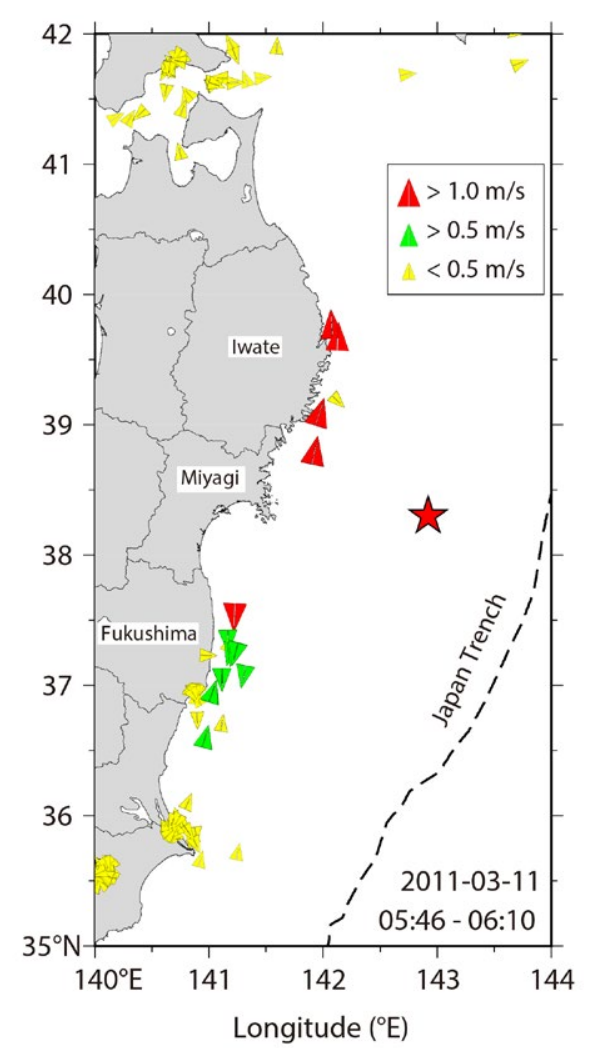

An image of tsunami current detection. 


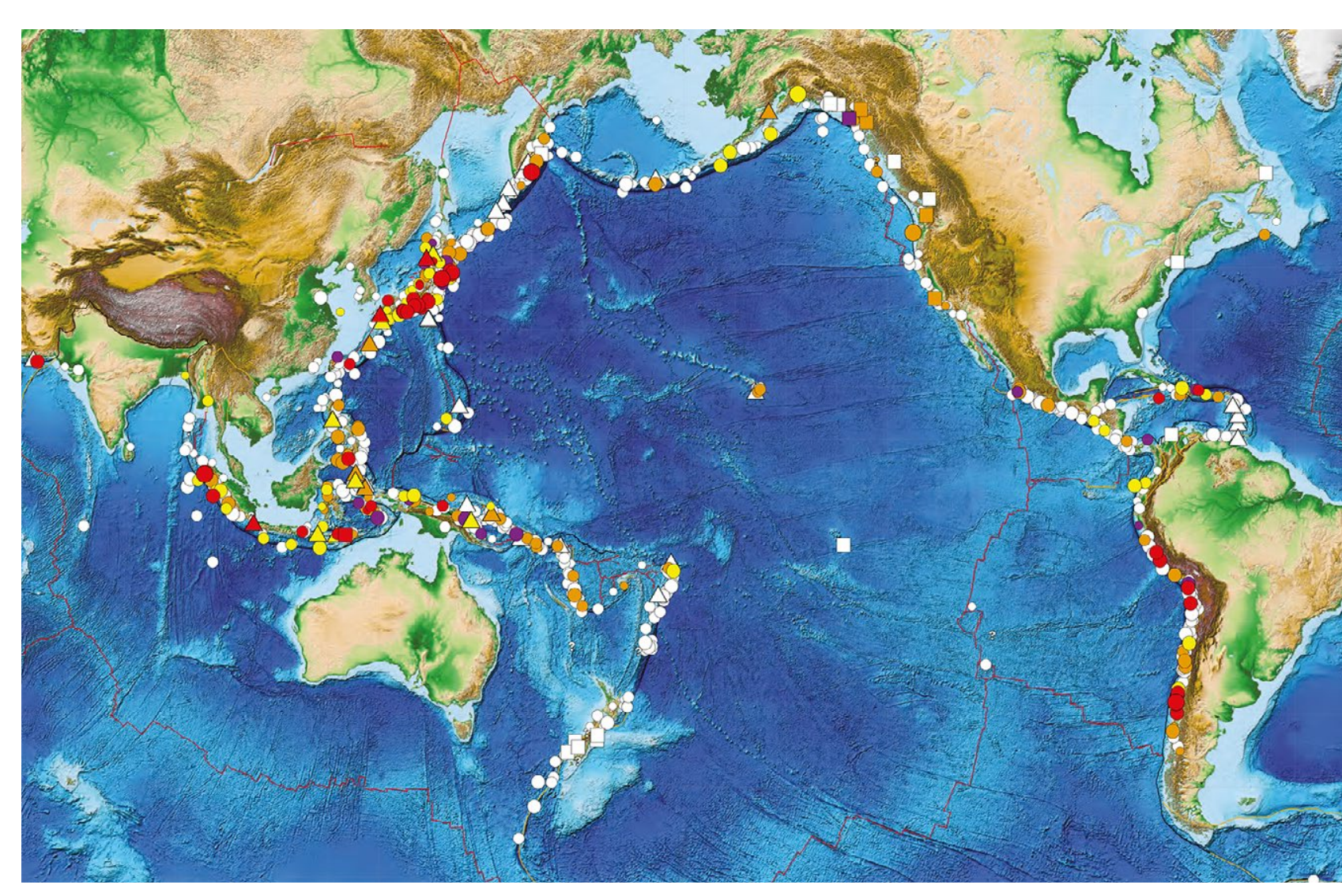

Historical tsunami sources around the Pacific of the 2011 Tohoku tsunam

The AIS data obtained from these ships indicated that COG significantly deviate from $H D G$ as the tsunami passes the ship. Using a mathematical model, they proved that ships immediately respond to tsunami current by moving in a diagonal direction with an equivalent sourcing AS data wil help to predict

\section{Ship Heading}

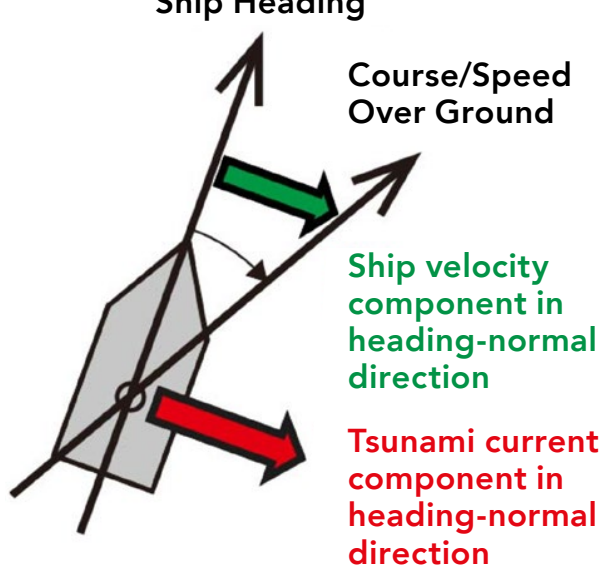

Ship velocity component in the heading-norma
direction is a clear proxy of tsunami current
Inazu and his research team are working on contributing to the lack of research regarding the use of AIS data to forecast tsunamis.

the source, magnitude and wave height of a tsunami.

What is so brilliant about this way of ships recognised by the AIS is

continually increasing meaning more and more data can be used around the world to forecast and measure tsunamis. This novel method of crowd-sourcing data has huge potential to change the way that coastal populations forecast tsunamis

Although there is more that could be done to increase AIS data reliability, Dr Inazu's research team is seeking to enhance the sensitivity of AIS data coastal and satellite AIS data. Using AlS data is a relatively cheap, promis way of measuring and forecasting South America will be able to use data paramount importance in many coastal of measuring tsunamis is possible to tsunami currents by using real-tim
THE FUTURE FOR THIS TECHNOLOGY employ offshore observatories to forecast countries do not have the econemic resources needed in order to set these up. However due to the low cost of obtaining AIS data, it is likely that obtained from ships in order to monitor and forecast tsunamis.

Tsunami disaster mitigation is of The use of AlS data for tsunami current monitoring may be a sustainable way of in areas where life loss prevention and While countries such as Japan already coastal cities in Southeast Asia and areas where large populations reside, which is what makes the work of Inaz and his fellow researchers so vital. ensuring that tsunamis can be mitigated

\section{Behind the Research}

Dr Daisuke Inazu

E: inazud@m.kaiyodai.ac.jp T: +81354630417 W: https://sites.google.com/site/inazud4ocean/

Research Objectives

Dr Inazu and his fellow researchers have conducted pioneering research into developing effective ways of monitoring and forecasting tsunamis by looking at the possibility of using Automatic Identification System (AIS) data of offshore navigating ships.

\section{Detail}

Department of Marine Resources and Energy, (1) 4-5-7 Konan, Minato, Tokyo 108-8477, Japan

\section{Bio}

Daisuke Inazu is an Associate Professor of the Departmen of Marine Resources and Energy at Tokyo University of Marine Science and Technology. He earned a PhD in Geophysics from Tohoku University, Japan, in 2007. His research experiences have been mainly based on numerica imulation of physics of the ocean such as tsunamis, tides,

Funding

tion of Science (JSPS)

- The Nippon Foundation

Collaborators

- Tsuyoshi keya, Tokyo University of Marine Science

and Technology, Tokyo, Japan

- Takuij Waseda, Toshivuki Hibiya UTokyo Ocean Alliance

The University of Tokyo, Tokyo, Japan

- Yoshinori Shigihara, National Defense Acadeny Kanagawa, Japan

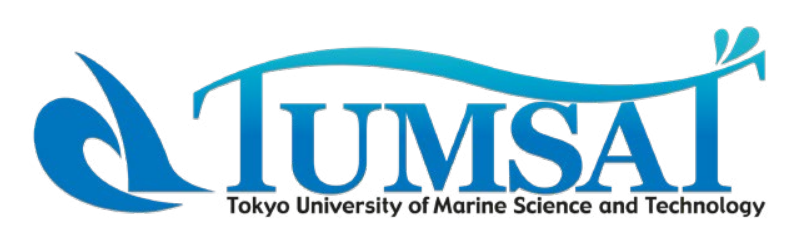

References Tang, L., Titov, W., Moore, C., Wei, Y. (2016). 'Real-time
assessment of the 16 September 2015 Chile tsunami and implications for near-field forecast'. Pure Applied Geophysics. (173, pages 369-387.

https://doi.org/10.1007/s00024-015-1226-3

Proud, R., Browning, P., Kocak, DM. (2016). 'AlS-based mobile satellite senvice expands opportunities for affordable global

Kong, Q., Allen, RM., Schreier, L., Kwon, Y-W. (2016) 'MyShake: A smartphone seismic network for earthquake early warning and beyond'. Science Advances: Volume 2, page

https://doi.org/10.1126/sciadv.1501055

Inazu, D., keya, T., Waseda, T., Hibiya, T., Shigihara, Y. (2018). Measuring Offshore Tsunami Currents using Ship Navigation Records'. Progress in Earth and Planetary Science: Volume 5,

https://doi.org/10.1186/s40645-018-0194-5

\section{Personal Response}

\section{What first piqued your interest in finding effective ways} to forecast tsunamis?

II My research idea was actually inspired by the smartphone seismic network proposed by the University of California, Berkeley. They utilise accelerometers embedded in our smartphones as seismic monitors from How about offshore? I was speculating tsun omi monit using information from navigating ships over the global

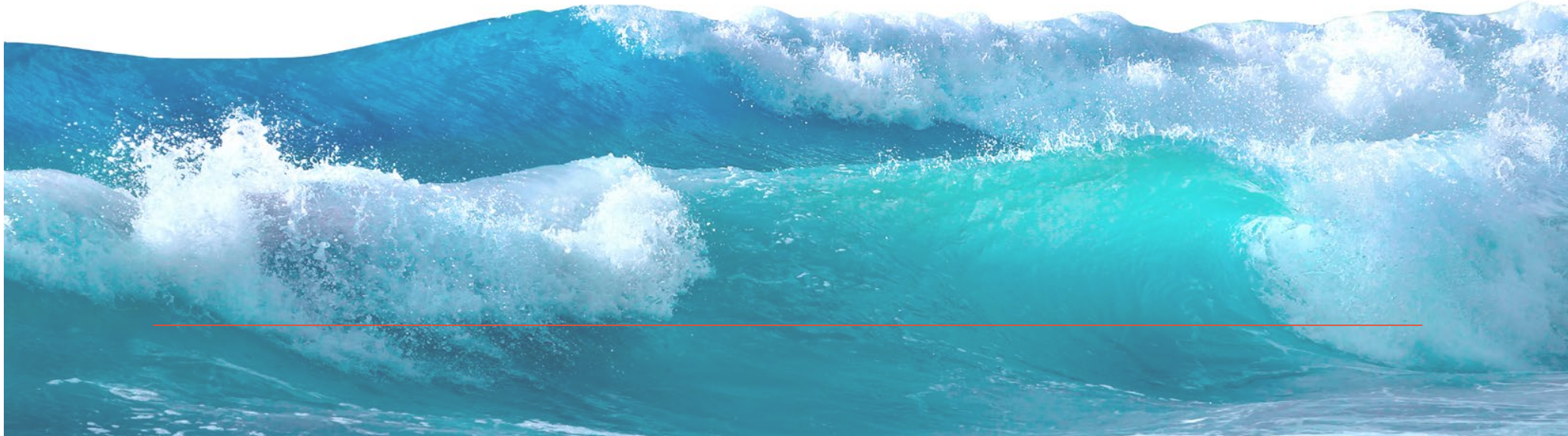

